\title{
Search for cross-reactivity between HLA B27 and Klebsiella pneumoniae
}

\author{
J. R. ARCHER
}

From the Immunology Section, Bone and Joint Research Unit, London Hospital Medical College

SUMMARY HLA B27 is associated with a number of forms of arthritis, including ankylosing spondylitis. It has been suggested that the disease is caused by Klebsiella pneumoniae and that the bacterium evokes an odd immune response because it cross-reacts with HLA B27. This proposed cross-reactivity was investigated in a number of ways. The results consistently failed to confirm evidence from cross reaction, even in antisera with activity against both HLA B27-positive lymphocytes and klebsiella. It is suggested that the anomalous anti-klebsiella response of rabbits immunised with pools of HLA B27-positive leucocytes may be caused by antigenic bacterial fragments on the cells of infected individuals.

HLA B27 is associated with a number of forms of arthritis-notably ankylosing spondylitis and Reiter's syndrome. Shigella flexneri, Yersinia entercolitica, Brucella abortus, and Salmonella typhimurium have all been implicated in triggering rheumatic attacks. ${ }^{12}$ The Ebringers and their colleagues have also suggested that many London area cases of ankylosing spondylitis are started by Klebsiella pneumoniae. Evidence for this has come in 3 forms. Welsh et al., ${ }^{3}$ working on the hypothesis that disease association with HLA haplotypes was caused by antigenic crossreactions between HLA and infective agents, tried to identify the agent by immunising rabbits with B27 positive cells and looking for antibacterial agglutinins. They found that rabbits developed antibodies against Yersinia enterocolitica and Klebsiella pneumoniae. It has further been reported ${ }^{4-6}$ that faecal carriage of klebsiella was higher in patients with active disease, or who were about to become active, than it was in nonspondylitic controls or patients in whom the disease was quiescent (although this result has been disputed ${ }^{7}$ ). More recently an Australian group $^{8}$ has shown that rabbit antisera to some strains of $K$. pneumoniae are cytotoxic for cells from certain patients but not against healthy B27 positive controls.

If the Ebringer cross-reactive hypothesis is correct, the following propositions should hold: (a) Cross-reactive rabbit anti-B27 lymphocyte serum

Accepted for publication 27 October 1980

Correspondence to Dr J. R. Archer, Immunology Section, Bone and Joint Research Unit, London Hospital Medical College, 25-29 Ashfield Street, London E1 2AD. should have B27 specificity. (b) It should be possible to remove anti-klebsiella activity from this serum by absorption with B27-positive cells. (c) Cross-reactive antigen should be demonstrable on the lymphocytes of patients with inactive disease as well as active spondylitis sufferers. (d) Rabbit anti-K. pneumoniae serum should have greater reactivity with B27positive than B27-negative cells.

This paper describes attempts to confirm these postulates and failure to find evidence for any of them.

An alternative explanation is needed for the high anti-klebsiella activity of some anti-B27 lymphocyte sera.

\section{Materials and methods}

Animals. Rabbits for immunisation were held in the animal house of G. D. Searle and Co, High Wycombe.

Bacteria. Klebsiella pneumoniae MX100, originally isolated from an ankylosing spondylitis patient at the Middlesex Hospital by Dr R. W. Ebringer and Mrs D. R. Cawdell, was obtained from Dr Ebringer and freeze-dried in gelatin capsules on arrival at the laboratory.

Lipopolysaccharide. Lipopolysaccharide (LPS) probably contained capsular polysaccharide as well as endotoxin. It was extracted by the phenol-water method of Westphal et al. ${ }^{9}$ from bacteria which had been grown on nutrient agar (Oxoid) and washed 3 times with saline. Further purification was carried 
out by precipitation with 5 volumes of ethanol. It was finally dialysed against distilled water to remove the last traces of phenol. The 'LPS' could not be precipitated by high-speed centrifugation at neutral pH but formed a heavy flocculent precipitate on addition of a few drops of acetic acid. The final product contained uronic acid $(7 \%$ by the Dische carbazole technique) and methyl pentose (10.5\% by the method of Dische and Shettles). ${ }^{10}$

Haemagglutination. Sheep red blood cells in Alsever's solution were washed 3 times in phosphate buffered saline (Dulbecco's A), resuspended at a concentration of $4 \%$, and mixed with an equal volume of LPS at $40 \mu \mathrm{g} / \mathrm{ml}$. They were incubated at $37^{\circ} \mathrm{C}$ for 1 hour with occasional gentle shaking and washed 3 times for 10 minutes at $200 \mathrm{~g}$. Aliquots $(20 \mu \mathrm{l})$ were added to doubling dilutions of antiserum $(20 \mu \mathrm{l})$ in Cooke U-welled microtitre trays. Trays were incubated at $37^{\circ} \mathrm{C}$ for 1 hour and checked for evidence of haemagglutination after storing overnight at $4^{\circ} \mathrm{C}$.

Tissue culture cells. Human B cells (BRI 8-HLA A1, A2, B8, B13) were grown in RPMI 1640 (Flow) containing $5 \%$ pig serum by Dr J. Birch in the cell culture unit of G. D. Searle and Co, High Wycombe.

Lymphocytes. Unless otherwise stated, lymphocytes were obtained from volunteers in the HLA typing panel of G. D. Searle and Co. Cells for cytotoxicity testing or absorption were obtained from heparinised blood by the Ficoll-Triosil method of Böyum. ${ }^{11}$

Immunisations. Two rabbit antisera ${ }^{3}$ against pools of HLA B27 positive lymphocytes were obtained from Dr A. Ebringer. Serum A was from a rabbit immunised with a pool of frozen lymphocytes from a panel of 83 normal B27-positive individuals. It had an antilymphocyte activity of about $1 / 1000$ and anti-Klebsiella haemagglutination activity of $1 / 128$. Serum B came from a rabbit immunised with cells from 3 patients who appeared to be homozygous for B27, and had a haemagglutinating titre of $1 / 512$. Other rabbits were immunised either intravenously or subcutaneously with lymphocytes from individual human donors $-10 \mathrm{ml}$ blood at fortnightly intervals.

Klebsiella for immunisation were grown overnight on McConkey or nutrient agar (Oxoid) and washed 3 times with saline. They were killed with either alcohol $(96 \%)$ or formalin and rewashed 3 times in saline. Rabbits were injected with an initial $10^{6}$ bacteria followed by doses of $10^{8}$ at fortnightly intervals. Two rabbits were immunised intra-peritoneally and one intravenously with formalin-killed bacteria, and two intravenously with alcohol-killed bacteria. Two further antisera made by subcutaneous injection with ultraviolet-light killed bacteria were obtained from Dr A. Ebringer.

Cytotoxicity tests. Cells for test (lymphocytes from $10 \mathrm{ml}$ blood or cultured cells) were washed 3 times in HEPES buffered Eagles basal essential medium (Flow) containing 10\% heat-inactivated fetal calf serum (10 HBEM), resuspended in 2 drops of medium, and mixed with $5 \mu{ }^{51} \mathrm{Cr}(20$ $\mu \mathrm{Ci} / \mathrm{ml}$ ) (Radiochemical Centre, Amersham). After incubation at $37^{\circ} \mathrm{C}$ for 90 minutes the cells were washed 5 times in $10 \mathrm{HBEM}$ and resuspended at $1 \times 10^{5} / \mathrm{ml}$. Test serum $(20 \mu \mathrm{l})$ was titrated in doubling dilutions in a $\mathrm{V}$-welled microtitre tray. Equal volumes of cells and pretitrated rabbit complement were added, and the mixture was incubated for a further 1 hour before further reaction was stopped by the addition of EDTA in saline and the amount of ${ }^{51} \mathrm{Cr}$ released was measured.

Absorption. Antiserum for absorption with BRI 8 cells was diluted $1 / 3$ with HBEM. Cells were washed 3 times in 10 HBEM and divided in 3 before the final wash. Antiserum $(1 \mathrm{ml})$ was added to the pellet in the first tube (containing approximately $3 \times 10^{8}$ cells) absorbed at $4^{\circ} \mathrm{C}$ on a rocking platform, centrifuged at $2000 \mathrm{~g}$ for 15 minutes, and then reabsorbed twice more. The final supernatant was centrifuged at $100000 \mathrm{~g}$ for 1 hour, and the absorbed serum was stored at $-20^{\circ} \mathrm{C}$ in $100 \mu$ l aliquots.

Human lymphocytes for absorption were obtained from $20 \mathrm{ml}$ of fresh heparinised blood on FicollTriosil. Antiserum diluted to $1 / 20$ was added to approximately $3 \times 10^{6}$ cells. After a single absorption cells were centrifuged out at $200 \mathrm{~g}$ and the supernatants tested.

\section{Results}

B27 SPECIFICITY IN 'CROSS-REACTIVE' SERA Rabbit anti-pooled B27 cell serum A, with an antiklebsiella haemagglutination titre of $1 / 128$, was absorbed with BRI 8 cells and tested for cytotoxicity against normal B27-positive and negative lymphocytes. In the course of 4 separate absorption experiments, with target cells from 3 B27-positive and 3 negative donors, no consistent difference was found in reactions against the 2 groups of cells. We concluded that there was no demonstrable specific antiB27 cytotoxic antibody in the rabbit anti-B27 lymphocyte serum.

\section{K. PNEUMONIAE SPECIFICITY IN \\ 'CROSS-REACTIVE' SERA}

Antiserum B (anti-pool from 3 patients) was absorbed with cells from B27-positive patients (from Dr R. W. Ebringer) or B27-negative controls. Three 


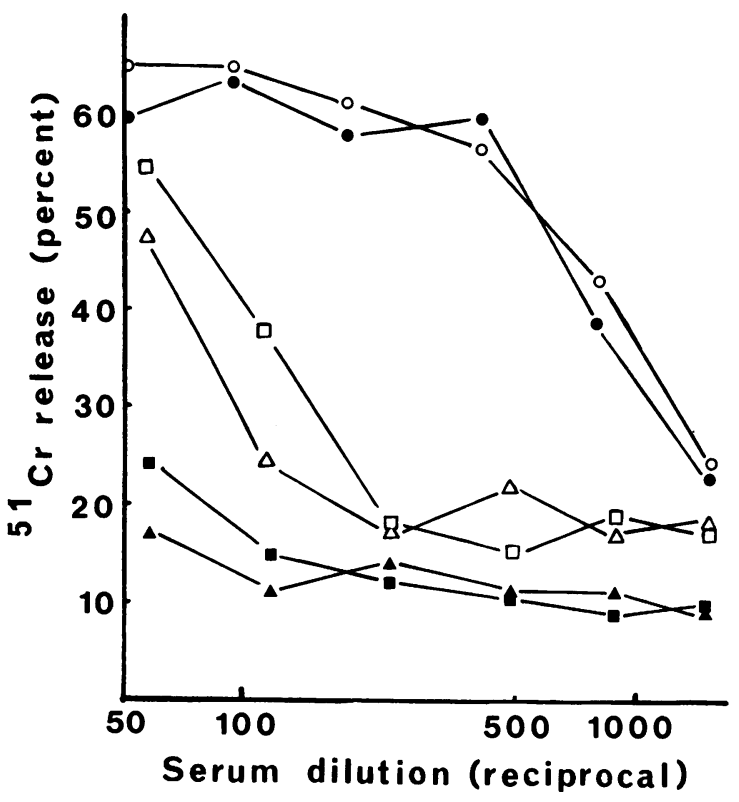

Fig. 1 Absorption of rabbit anti-B27 lymphocyte serum with lymphocytes from a B27-positive patient with ankylosing spondylitis and a B27-negative control. Open symbols = patient's cells as target (HLA B27). Closed symbols $=$ control cells as target (HLA A9, $A W 31, B 5, B 15) . \bigcirc, \bullet=$ Unabsorbed. $\Delta, \Delta=$ Absorbed with patient's cells. $\square, \square=$ Absorbed with control cells.

tests were carried out with cells from a total of 3 patients, 2 healthy B27-positive individuals, and 4 healthy B27-negative controls. Typical results of cytotoxicity tests on these sera are shown in Fig. 1.

The same samples were tested for klebsiella haemagglutinating activity before and after absorption. In each case, whether the absorption was by cells from patients or from controls, the titre fell from $1 / 512$ to $1 / 320$.

The results are unsatisfactory because it was not possible to obtain enough lymphocytes to carry out a complete absorption on the serum. It is clear, however, that an absorption which removed $90 \%$ of the antilymphocyte activity from the serum had only a slight nonspecific effect on its anti-klebsiella activity, and it seems most likely that the antihuman and anti-klebsiella activities are on separate molecules.

IMMUNISATION WITH CELLS FROM

B 27-POSITIVE INDIVIDUALS

Cells from a 34-year-old male (HLA A1, A11, B44, B27) who claimed that he had been healthy for many years were used to immunise 3 rabbits at fortnightly
Table 1 Cytotoxicity of rabbit anti-klebsiella sera against B27-positive and negative lymphocytes

\begin{tabular}{lll}
\hline & & $51 \mathrm{Cr}$ release \\
& $\geqslant 20 \%$ & $<20 \%$ \\
\hline B27-positive & 6 & 59 \\
B27-negative & 6 & 56 \\
\hline
\end{tabular}

intervals intravenously for 1 year and 2 subcutaneously over a period of 4 months. The animals were bled regularly to look for anti-klebsiella activity but none was found.

We concluded that immunogenic klebsiella-like antigen was not invariably present in HLA B27positive cells. It seemed more likely either that the original anti-klebsiella activity in sera A and B was an artefact or that antigen is present only sporadically.

\section{CYTOTOXIC ACTIVITY OF ANTI-}

KLEBSIELLA SERA

Eight rabbit anti-klebsiella MX100 sera were tested for cytotoxicity reactions against a panel of normal and B27-positive cells. A few tests showed slightly high ${ }^{51} \mathrm{Cr}$ release at the greatest antiserum concentration, but this could be rapidly titrated out. Table 1 shows the number of tests on B27-positive and negative normal cells giving a release of more than $20 \%$ in one of the first 2 wells of the titrations. (Background and full release are approximately $10 \%$ and $70 \%$ respectively). Cells from a total of 12 B27-positive (including 3 patients), and 11 B27negative individuals were used. The healthy B27positive donors included a symptom-free person who had had Reiter's syndrome diagnosed 2 years previously. Cells from this person did not differ significantly from the others. There was clearly no reaction between anti-klebsiella serum and the cells of the healthy individuals tested, even though at least 1 appeared to carry the genetic susceptibility to HLA B27-associated arthritis.

\section{Discussion}

This paper describes how we attempted and failed to find evidence for cross-reaction between HLA B27 and Klebsiella pneumoniae MX100 by a number of conventional tests, many using the original sera and bacterial strain used to define the cross-reaction. It can always be argued, with negative results, that the experimental model was not sufficiently sensitive to detect the true result. However, I think it unlikely that the 'cross-reaction' we were seeking would have been very difficult to detect. The rabbit antilymphocyte sera had substantial anti-klebsiella titres by the haemagglutination assay ('normal' sera 
tested in the same system seldom had titres greater than $1 / 20$ (Welsh, unpublished)). In spite of this our complement-dependent cytotoxic assay could detect no specific B27 activity in what should have been the same population of antibodies directed against the homologous system. Although a few examples are reported of situations in which antibody is more potent against a cross-reactive than a homologous antigen (original antigenic sin, ${ }^{12} 13$ heteroclitic antibodies ${ }^{14}$ ), these generally involve a primary response, and the effect is reduced on further immunisation: the rabbit sera here described are hyperimmune.

The cross-reactive hypothesis poses chemical difficulties. HLA antigens are heat-labile proteins. That they should cross-react with antigens extracted from a hot phenol soup is implausible.

It could be argued that if association of susceptibility to arthritis with HLA B27 is caused by a gene in close linkage disequilibrium, and not B27 itself, our panel of nine 'normal' B27 individuals lacked the appropriate gene. This also seems unlikely. The panel included at least 1 individual with a history of B27-associated arthritis.

If the high anti-klebsiella titre of anti-B27 pooled lymphocytes is accepted as genuine, the simplest explanation of these results is that klebsiellareactive antigen is found on lymphocytes of B27positive persons only sporadically. This agrees with the observation of Seager et al. ${ }^{8}$ that anti-klebsiella serum reacts only with lymphocytes from certain patients with ankylosing spondylitis and not with cells from normal B27-positive controls. The most likely source of antigen is klebsiella, and the activity of the Ebringer sera is attributable to inclusion of lymphocytes from affected individuals. On this hypothesis HLA B27 acts as a marker for a processing defect in the cells of certain individuals which makes their leucocytes pick up certain Gramnegative bacterial antigens but fail properly to handle them (perhaps to pass them to another cell to elicit an immune response). Cells carrying antigen would act as immunogens when injected into rabbits in Ebringer's system, or act as targets for cytotoxic reactions in the experiments of the Sydney group. ${ }^{815}$ How the reaction of bacterial products with HLA antigens leads to arthritis is still a matter for speculation.
Most of the experimental data in this paper were obtained by Miss C. J. R. Welsh, and form part of her PhD thesis submitted to the University of London. It is a pleasure to thank her for her intelligent and skilful collaboration, as well as access to her data. I would also like to thank Dr A. Ebringer and Dr R. W. Ebringer for the supply of rabbit antisera and their 'cross-reactive' strain of klebsiella.

\section{References}

1 Ryder L P, Andersen E, Svejgaard A. HLA and Disease Registry Third Report. Copenhagen: Munksgaard, 1979.

2 Hodinka M, Gömör B, Merétey K, Zahumensky Z, Géher P, Telegdy L, Bozsóky S. HLA-B27 associated spondylarthritis in chronic brucellosis. Lancet 1978; i: 499.

3 Welsh J, Avakian H, Cowling P, et al. Ankylosing spondylitis, HLA-B27 and Klebsiella. 1: cross-reactivity studies with rabbit antisera. Br J Exp Pathol 1980; 61: 85-91.

4 Ebringer R, Cooke D, Cawdell D, Cowling P, Ebringer A. Ankylosing spondylitis: Klebsiella and HLA B27. Rheumatol Rehabil 1977; 16: 190-6.

5 Ebringer R W, Cawdell D R, Cowling P, Ebringer A. Sequential studies in ankylosing spondylitis. Association of Klebsiella pneumoniae with active disease. Ann Rheum Dis 1978 ; 37: 146-51.

6 Eastmond C J, Willshaw H E, Burgess S E P, Shinebaum R, Cooke K M, Wright V. Frequency of faecal Klebsiella aerogenes in patients with ankylosing spondylitis and controls with respect to individual features of the disease. Ann Rheum Dis 1980; 39: 118-23.

7 Warren R E, Brewerton D A. Faecal carriage of klebsiella by patients with ankylosing spondylitis and rheumatoid arthritis. Ann Rheum Dis 1980; 39: 37-44.

${ }^{8}$ Seager K, Bashir H V, Geczy A F, Edmonds J, de VereTyndall A. Evidence for a specific marker on lymphocytes of patients with ankylosing spondylitis. Nature 1979; 277: 68-70.

- Westphal O, Lüderitz O, Bister F. Über die extraction von bakterien mit phenol/wasser. $Z$ Naturforsch 1952; 7b: 148-55.

10 Kabat E A, Mayer M M. Experimental Immunochemistry. 2nd ed. Springfield: Thomas, 1961: 522-3, 538-40.

11 Böyum A. Separation of white blood cells. Nature 1964; 204: 793-4.

12 Fazekas de St Groth S, Webster R G. Disquisitions on original antigenic sin. I: Evidence in man. J Exp Med 1966; 124: 331-45.

13 Fazekas de St Groth S, Webster R G. Disquisitions on original antigenic sin. II: Proof in lower creatures. J Exp Med 1966; 124: 347-61.

14 Imanishi T, Mäkelä $O$. Strains differences in the fine specificity of mouse anti-hapten antibodies. Eur J Immunol $1973 ; 3$ : 323-30.

15 Geczy A F, Alexander K, Bashir H V, Edmonds J. A factor(s) in Klebsiella culture filtrates specifically modifies an HLA-B27-associated cell surface component. Nature 1980; 283: 782-4. 